Poster Section

\title{
Standards for comparing validity of different treatment methods: the "five E framework"
}

\author{
Giovanna Silvestri \\ Rehabilitation Unit of $26^{\text {th }}$ Health District, Naples, Italy
}

\begin{abstract}
Background and Aims. Evidence Based Medicine (EBM) neglects factors extrinsic to science. To bypass such a limitation, a global approach for validation of treatment methods is proposed. In addition to effectiveness, further standards are required, in order to include priority issues like bioethics, environment preservation, global financial crisis, and undeclared conflict of interest.
\end{abstract}

Methods. We suggest to evaluate any healing system within a "five E framework" by applying the following standards: 1) evidence (see EBM), 2) epistemology, 3) ethics, 4) ecology, and 5) economy.

2) Preliminary adaptation of any research to the epistemological background of the treatment to be evaluated is needed, in order to compensate for the poor compliance of EBM methodology to holistic methods. The restrictions imposed by the rules of classical epidemiology to study design (see case definition and standardization of treatment) can completely twist the analysis of results.

3) The ethical standard implies giving attention given to treatment invasiveness, related both to life of animals employed in experimental studies and to side effects on health of human volunteers or patients.

4) The ecological standard, consisting in the implications of pharmaceutical production on environment, should be analyzed in terms of ecological footprint, i.e. for the global effects of industrial waste on ecosystems and species.

5) The economical standard evaluates both the impact of financial crisis and the role played by conflict of interest, comparing allopathy with holistic systems.

Conclusions. The "five E framework" seems more adequate, for several reasons, to validate homeopathy or other treatment methods, if compared with the sole EBM approach.

Misunderstanding of results and consequent publication bias can be avoided by adhering, in study design, to the philosophical foundations of homeopathy, i.e. by choosing a remedy according to the law of similars and the totality of symptoms - individualization of treatment.

On the ethical plane, in the case of homeopathy, apart from the absence of drug toxicity and the possibility of avoiding vivisection for experimental purposes, even in the production of drugs from animal species, induction of death can be prevented or strongly circumscribed.

About effects on environment, allopathic drug waste causes pollution, alters the features of a given species, or modifies the balance between different species, while the employment of large quantities of natural active principles in drug industry has an impact on biodiversity. Homeopathic industry has no relevant effects on environment, because slag release is insignificant and the productive process is highly efficient. 
Finally, homeopathy meets relevant economic issues: a) while management of crisis by states with a health system mainly oriented to allopathy imposes a heavy burden to community by reducing public funding of health care, the high sustainability of all holistic systems limits the risk of worsening health care level; b) homeopathy is less subject than allopathy to undeclared conflict of interest; the enormous margins of profit and the chance of competition issued by big allopathic industry have a limited role in classical homeopathy.

Key words: bioethics, EBM, ecology, economy, epistemology

\section{(c)) BY-NC-ND Licensed to GIRI}

Support: the author declares that this study received no funding

Conflict of interest: the author declares there is no conflict of interest

Received: 01 June 2012; Revised: 10 August 2012; Published: 30 September 2012.

Correspondence author: Giovanna Silvestri, giosilvestri63@gmail.com

How to cite this article: Silvestri G. Standards for comparing validity of different treatment methods: the "five E framework". Int J High Dilution Res [online]. 2012 [cited YYYY Month dd]; 11(40):188-189. Proceedings of the XXVI GIRI Symposium; $2012 \quad$ Sep 20-22; Florence (Italy). GIRI; 2012; Available from: http://www.feg.unesp.br/ ojs/index.php/ijhdr/article/view/611/601 